\title{
Watching Alice: The Child as Narrative Lens in Alice's Adventures in Wonderland
}

\author{
Rachael Cameron
}

$\mathrm{T}$ his essay will critically evaluate the representation of childhood constructed in the 1865 'nonsense' text, Alice's Adventures in Wonderland, by Lewis Carroll (Charles Dodgson). The popularity of this narrative (which has been translated into over fifty different languages) and its sequel, Through the Looking Glass, is unquestionable, with some sources claiming that these texts are, 'next to the Bible and Shakespeare, the most quoted books in the English language.' (Vink 1998). Over one hundred and thirty years after its initial publication, Alice's Adventures in Wonderland remains a rich textual source for contemporary literary criticism and intertextual re-inscription. The cultural centrality of this text is further evidenced by the existence of an industry (the Lewis Carroll Socjety) consisting of a clan of serious international fans.

A form of cultural collateral, Alice's Adventures in Wonderland has been adapted into other mediums such as: the visual arts, theatre, ballet, cinema, music videos and puppetry. But perhaps the uncanniest 'proof' that this author (and his work) occupies a symbolically charged and central space in our cultural imagination, is the photographic image of Carroll - as a metonymic component, or puzzle piece in a constructed collage included in the cover of the Beatles' psychedelically inflected album, Sergeant Pepper's Lonely Hearts Club Band. The aim of this essay will be to challenge the Beatles' claim that 'all you need is love.' It will instead argue that contemporary tools (particularly those drawn from the field of reception theory) are required to demarcate a model of desire (or counter-narrative) within this text, and within our own culture.

\section{Subversion in language}

This essay does not intend to detract from the 'fun' of Carroll's predominantly unconscious language game. It does however, ask for a more critical reading of this text; a reading which is based on the text's own terms, and according to its own principles. From this theoretical position, Carroll's use of particular signifying practices and the ideologies these presuppose - is problematic. Like the critic Roderick McGillis, this author believes that 'if Alice is the subversive book I think it is, there can be no protection for us, unless of course, we misread the book' (1986, p.29).

This essay therefore contends that the critical (and historical) reception of this text as 'nonsense' literature; the assertion that it is nothing more and nothing less than an amalgamation of fantasy and humour, allows previous readings of Alice in Wonderland to be interpreted as denials of the space this literary technique inscribes. By employing a deconstructive analysis of the roles and relationships that exist between language, ideology and ethics, disguised textual contents previously obscured by the text's veiled form of language use are revealed. When these fragments, and the patterns they form, are analysed, the findings support the comments of Martin Gardner and Joan Aiken, who have suggested that for readers of this text 'and perhaps at times for Alice, this dream is a nightmare' (in McGillis 1986, p.26).

Writing, the unconscious, and desire

Through the formal logic of the unconscious (that is, the logic of nonsense as other to consciousness) Carroll's text uses the scene of writing to exteriorise a model of desire based on similarity. In the narrative world of Alice in Wonderland, difference within and between linguistic and other registers effaced. As a conscious or unconscious sign, Carroll's text thus erases the specificities which differentiate between the registers of sexuality and textuality, subject and object, past and present, reality and fantasy, language use (as a form of symbolic ordering) and the unconscious (as a site of frayage or destructuring). This text, which uses the unconscious as a scene of writing, uses atemporal signifying structures and is without causal relations. Like the unconscious itself, it is therefore an assemblage of multiple contradictions.

As agift, sign, or symptom, Alice's Adventures in Wonderland furthermore inscribes a territory where desire is an intervening term. Desire is thus a projected (textual) appeal, an imperative or message transmitted in advance of its receiver. This essay will argue that this text contains and exposes uneasy internal and metatextual alliances by unsettling the formal conventions that have traditionally governed what is recognised as adults' and children's discursive registers.'

Constructing childhood

Many literary critics agree that historically, 'the child' - 
as a construction - was "invented in the late eighteenth century to occupy an empty psychic and social space.' (Kincaid 1992, p.11). Where in earlier periods childhood sexuality was a matter of indifference, in the nineteenth century, the child (according to Foucault) was sexualised. As James Kincaid points out in Child-loving: The Erotic Child and Victorian Culture, the image of the child which is 'formulated in response to desire is really a complex and dynamic function' (1992, p.195). The ethical question that must therefore be asked in relation to this text is: what sort of love, what type of appeal or imperative is encoded and being transmitted, through the narrative world of Alice's Adventures in Wonderland, to contemporary children?

\section{Focalisation}

Alice's Adventures in Wonderland comprises a series of staged adventures, and is perhaps best described as a spectacle that enacts excess in a representational field where distinctions between reality and fantasy are blurred. ${ }^{2}$ Alice's role in this world of play is to focalise narrative events. Throughout the text Alice is continually looking: she seeks familiar (visual) signs - orientating markers - in the belief that they will help her define herself and her position in this unfamiliar world. In 'Down the RabbitHole,' we observe as Alice 'looked up, but it was all dark overhead' (1970, p.29). Later, we 'see' her kneel down 'and look ... along the passage into the loveliest garden you ever saw' (p.30). In 'The Pool of Tears' we watch as she 'looked down at her hands, and was surprised to see that she had put on one of the Rabbit's little white kid gloves while she was talking' (p.39).

Alice therefore uses her perceptual apparatus (which is active, dynamic and 'free floating' in perspective) to draw narrative objects and landscapes into her field of vision. Yet paradoxically she is simultaneously positioned as an object of the narrative gaze. That is, narrative information (the narrative world as 'drama' or play) is acquired by this character, but her awareness of events is never complete or conclusive, as this data is itself filtered through the narrating consciousness. Alice functions as the reader's point of access into Wonderland's register of fantasy; yet her agency is conditioned and limited by the role in which she has been cast in this drama.

\section{The gaze}

The gaze exceeds sight. It is more than looking. In Freudian terminology, it involves scopophilic and epistemophilic (psychic) drives whose aims are displaced onto visual and conceptual representative fields through the acts of 'looking and ... gaining knowledge' (Freud 1982). Yet the gaze does not merely interpret reality through the optical translation of a particular object's form. It actually constructs, produces reality by formulating or mapping a conceptual image; this is produced by the 'I' of a perceiving subject (Foucault 1977, p.45). The gaze therefore informs perception and, through the repetition of images of association, ultimately preconditions the structures that model various forms of consciousness. According to Foucault the gaze is telescopic and functions as a multi-dimensional model of perception. He states:

\section{ILJying behind each eye that sees, there exists a more tenuous one ... behind this particular eye, there exists another and, then, still others, each progressively more subtle until we arrive at an eye whose entire substance is nothing but the transparency of its vision. This inner movement is finally resolved in a non-material center where the intangible forms of truth are created and combined, in this heart of things which is the sovereign subject.}

(Foucault 1977, p.45).

\section{Point of view}

Furthermore, the ' $\mathrm{I}$ ' of the gaze, when it is directed to erotic or libidinal sites, induces pleasure (Barthes 1994). It also implicates sexuality; that is, the gaze takes the form of a substitute satisfaction; it is an aim-inhibited activity that occurs predominantly in the field of representation (Freud 1982). In Alice's Adventures in Wonderland, we, as readers, are spectators while Alice dominates our point of view. We 'see' Alice in a mediated fashion however; which is 'through the eyes of the narrator' (McGillis 1986 , pp.32-33). This inscriptive technique can be aligned with a model of desire which textualises the subject; allows it to be treated as 'a pleasurable story or movie run in the head rather than an event' (Kincaid 1992, p.260). 
What is significant in this movement of the narrative is the subtle substitution that distances, thereby allowing the subject to be transformed to an 'it' (object) as opposed to a subject.

The adult and the child

In this text that is other to consciousness, an uneasy alliance exists between the gaze, knowledge and childhood (as a site of value). By analysing the images and positioning of the child in Alice's Adventure's in Wonderland, an interdependent relationship between discourses of childhood and spectatorship becomes apparent. This relationship is however, contextually influenced. For Carroll and indeed Victorian culture, 'talk on children, on the body, and on sex did not dissociate but combined the three, did not make the figures of the erotic child's body unthinkable' (Kincaid 1992, p.183). But Carroll's text, as evidenced in its free play in and with language, and its resistance to the adult world, is unique, making it important to note that the Victorians, like ourselves, also experienced confusing differences and contradictions within elements of their own culture.

The empty child

In 'Down the Rabbit-Hole,' Alice, as the protagonist of Carroll's unconscious narrative, is represented languidly. Sleepy and stupid from the heat of the afternoon sun, Alice is described as "beginning to get very tired of sitting by her sister on the bank, and of having nothing to do' (p.25). At this textual location, Alice is positioned in a state of boredom, her inner life elided. Devoid of signification and positioned at a perceptual limit, Alice nonetheless remains a site of value. Alice - as an object of desire - is valued precisely because she is empty; her subjective vacancy makes her desirable as a potentially occupiable site.

\section{Wonderland: the field of the Other}

Motivated by curiosity, which is seen by Maria Tartar as the cardinal sin for subjects in Victorian literature (Tartar 1992), Alice impulsively follows a white rabbit down its hole, 'never once considering how in the world she was to get out again' (p.26). From this site of fertility (also a liminal point where unknown realms of experience are accessed) Alice descends, or theologically 'falls', into a space of signification. In this space, relationships are reversed and distorted. Time and space are calculated though absence, deceleration, and an altered relationship to gravity. An absence of light initially characterises this environment with Alice trying 'to look down and make out what she was coming to, but it was too dark to see anything' (p.26). Her descent is not rapid: she 'fell very slowly ... [and] ... she had plenty of time as she went to look about her, and to wonder what was going to happen next' (p.26). Wonderland may be then considered a metaphor of the unconscious, which Jacques Lacan also considers the field of alterity (Lacan 1994, p. 187).

\section{The child as Other}

The world that meets Alice's gaze is represented through icons of domesticity and literacy: 'she looked at the sides of the well, and noticed that they were filled with cupboards and bookshelves: here and there she saw maps and pictures hung upon pegs' (pp.26-7). This space may be likened to Kristeva's semiotic chora, whose undifferentiated, material components are as yet asignifying, but are integral to and the pre-condition for signification (Kristeva 1984). Alice attempts to 'read' these objects and construct meaning in this world, but the world that Carroll 'maps' for his protagonist is distorted and defamiliarised with temporal and developmental relations reversed. So, as we (the readers of the text) 'are sliding down toward the child, the child is roaring past us in the opposite direction, growing up.' (Kincaid 1992, p.279). This defines the child's status as fluid, Other. In Wonderland, Alice (unlike other children) appears able to do the impossible, which is to 'be held, kept as a child' indefinitely' (Kincaid 1992, p.270). The aim in Wonderland - where consequences do not necessarily follow actions - is therefore to hold the child and defy time and transience.

\section{Textuality/sexuality}

The narrative begins lyrically with the poem All in the Golden Afternoon. As a framing device, this title connotes from the outset a convergence of themes and sites that can only be considered (from a contemporary viewpoint) problematic. Most notably, this convergence implicates 
discourses of innocence, the child and the Golden Age, which is perceived as, and displaced onto, an actual bodily site or developmental stage. As a retrogressive metanarrative, this poetic fragment can, furthermore, be characterised by a desire by the narrating consciousness to return to origins. That is, this introductory textual fragment re-capitulates (in order to revisit the pleasures of the text) the scene of its own conception. Stanza one reads:

All in the golden afternoon

Full leisurely we glide;

For both our oars, with little skill,

By little arms are plied,

While little hands make vain pretence

Our wanderings to guide.

(1970:21)

At this site the (metonymic) components of the lake, oars and littie hands, all work in unison to achieve the journey's (or narrative's) end. As such, these leitmotifs metonymically represent a fantasy of union which is brought about by an effacement of difference in differing representational registers. So, while this poem conforms in style and structure to the adult literary register of Romanticism, this is problematic, given that a counter narrative - which attempts to promote similarity - exists within the inscriptive space of this narrative. And, it is this counter narrative which would efface the very real disparities in life experience that exist between the sender and receiver/s of this text.

In Carroll's context, which is nineteenth century England, '[r]omantic love borrowed from the sacrament of confession, the religious language of avowal, the redemption of suffering, and the anticipation of reward. (Perrot 1990, p.570). While ostensibly a romantic discourse, this essay will contend that Carroll's use of metaphors of desire throughout this narrative is questionable. This is because the insertion of this specific form of consciousness, and with it the application of a particular model of desire, within the inscriptive space (aiso known as the scene of writing) does tend to blur certain boundaries and distinctions which would otherwise be disqualified, as they are not socially sanctioned, by the dominant culture. Kincaid reiterates this point (which is that this poem blurs the distinctions that exist between adulthood and childhood). He interprets the textual fragment above as 'a basking verse, one that laps and strokes and suggests a recapture in memory so perfect that the past will flood the present, erasing that distinction and, with it, the one between the adult and the child.' (Kincaid 1992, p.293).

Ostensibly, Carroll's later appeal - via the genre of poetry - to the recipient of his textual gift, the real Alice Liddell, appears innocuous enough. He writes:

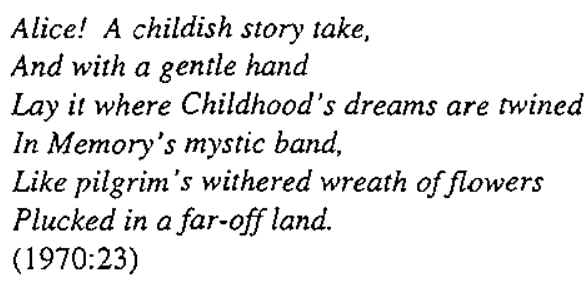

This final stanza of the poem is presented as a form of past/ancient, yet highly personalised history. And it is by accessing this history - through the poem as an archaeological remnant - that the return to a romanticised, nostalgic, and therefore highly idealised, past may be achieved. As such, this poem is an address to a reading other that may also be interpreted as an imperative. Its appeal, quite simply, is to keep the story and its associated pleasures alive. Yet there is contradiction here as well, for in this reading, the signifier of the pilgrim's "withered wreath of flowers" also suggests stasis, sacrifice, death and decay. The dehydrated wreath of flowers can therefore also be interpreted as connoting religious iconography whose language and rituals (symptomatically) 'speak' disavowal and repression. For Carroll encodes the giver of the wreath, the relinquisher of the bodily text as an omnipotent, unquestioning creator and a Christ-like, sacrificial or martyred lover.

Pleasure is therefore defined in this text through negation: that which it is not. So, if love relations are defined counter-discursively in Alice in Wonderland, could it be that this text is not just an innocuous tale for children? Could it also be interpreted as an erotic valorisation of suffering and repression? 
Eden: a site of temptation and seduction

The narrative world of Alice's Adventures in Wonderland, which consists of veiled references to temptation, sin and fallen bodies, represents childhood through ontotheological discourses, as a site that is altemately paradise found and paradise lost. Paradise is dispiaced because of the conditions of childhood. An impossible desire - to hold an elusive childhood - thus forms the dynamic tension of the text. The erotics in Wonderland depend on 'a fluid, shifting Other, sliding in and out of focus, offering glimpses and then taking them away, rescuing the adult from despair and then abandoning him' yet this is impossible, because children fall, "let themselves down ... [by] ... growing up, becom[ing] truly lost' (Kincaid 1992, pp.295, 279). The conditions of childhood are that it is neither static, nor permanent, but a developmental phase. As such it is temporally limited.

\section{The child as object of desire}

In a subversion of discourses of childhood and innocence, Alice is positioned in 'Advice from a Caterpillar' in a theological, Edenic setting. At this site, her status as an object of the gaze, or as a child stretched in between worlds, is revealed. After ingesting a portion of a possibly hallucinogenic mushroom, Alice experiences alterations, whose results are not pre-determined, in her physical status. Through such biological processes or changes as diminution and magnification, Alice can become both little and big. After this event, Alice metamorphosises into a phallicised Serpent or agent of seduction: 'As there seemed to be no chance of setting her hands up to her head, she tried to get her head down to them, and was delighted to find that her neck would bend about easily in any direction, like a serpent' (p.74). At the site of this metaphoric garden, Alice is accused by the Pigeon, an embodiment of moral and maternal agency, of sin and untrustworthy motives. After all, what (given the connotations of the garden as a sexualised site) is Alice doing here?

According to the Pigeon's 'I must be on the look-out for serpents night and day!' (p.75), Alice represents antimaternity. As a sexualised threat, she is an agent that 'swallows' eggs and 'kills' potential children. Alice's eroticisation (she is an object of desire) and its conjuncture with chaos is questionable in Carroll's re-inscription of the theological fall. Resistance in this text is directed toward the external, adult world, while the colonisation of the textual protagonist subversively exteriorises the narrative's unconscious structures of desire. Privileging fantasy and dependent on it, this text is perhaps best interpreted as a drama of perpetuation. It is endlessly revisable and (as it occurs in the imaginary register) self satisfying. The aim of this form of narrative is therefore non-closure, the function of the narrative being to keep the drama (and with it, desire) alive.

\section{A psychology of resentment}

While Alice inspires fear and mistrust because she cannot be contained (since her size and form are alterable), this textual representation effaces the very real contextual confusion and fear individuals experience in regard to their own bodily changes. That is, Alice is herself uncertain as to her own identity: "II - I'm a little girl," said Alice, rather doubtfully as she remembered the number of changes she had gone through, that day' (p.76). She is herself challenged and potentially alienated from her own subjective experiences by the flows, pulsations and 'foreign' articulations of her own developing materiality. Furthermore, some critics have stated that 'Alice certainly suffers an identity crisis in Wonderland.' (McGillis 1986, p.29). In what must then be considered a disturbing ideology, guilt or contempt (for the frustration of a desired outcome) is displaced onto the child protagonist who is in turn perceived as responsible for bodily changes over which she has, in fact, limited agency.

\section{Carroll as Pygmalion}

In the encounter with Carroll as Pygmalion, the protagonist, as other, is without agency. She has been granted the gift of life, but this is not her own to enjoy. Alice therefore represents the limits of love and representation in children's literature. She is a sculpted object whose ultimate form is dictated not by her own desires, but is constructed according to those of her creator's. That is, 'Alice seems trapped, given only the power to resist, to decline invitations but never accept 
them' (Kincaid 1992, p.290). Denied a subjectivity and agency of her own, Alice - like the statue of Galatea - is not able to tell her own story. Lacking desire (for this belongs exclusively to God / the creator / the writing subject) she is unable to represent herself. Alice as protagonist therefore cannot be considered a subject of the narrative gaze in Alice's Adventures in Wonderland. She is not a subject interfacing with, and reciprocating relations in her narrative world; she is instead an object or a product, and her desires are not her own. Alice (as an exotic Other) functions in this text as a mirror that is also a window 'reflecting back to the adult viewer a child, a true child ... [which is seen as] .... complex narcissistic image offering entry into a vision of play' (Kincaid 1992, p.295).

Anarchy and the outside (adult) world

Alice, Carroll's dream-child, ostensibly represents a resistant subject, an inversion of the commonplace that Victorian children should be seen and not heard. Alice articulates, she speaks, but her 'words are not her own' (Irigaray, 1983, p.99). So, if she is a resistant subject in a world that self-consciously professes 'we're all mad here. I'm mad. You're mad' (1970:89) then her resistance is a lie. The Victorian context considered children's bodies, like children themselves, to be innocent, so it is not surprising that Alice is represented textually as a 'plasticine girl.' That is, her body is docile and malleable. Throughout the narrative, her corporeality is pushed, pulled, stretched, squashed and modified. Alice nearly drowns in her own tears, she passes through a keyhole and is uncomfortably contained within domestic spaces.

The external environment is also depicted as a place where shapes shift and inner and outer barriers move. Threatening inner and outer worlds, like the collapsing house of cards at Wonderland's end, mark the limit of the Limit of meaning in this text, which is not nonsense, but what has been identified by McGillis as 'a fine madness' (1982, p.29). Like anarchy (which Kincaid defines as the political celebration of play) this fine madness 'seeks to blow up the wholly illegitimate world of the adult, and build in its play the free kingdom of the good child.' (Kincaid 1992, p.231). Yet this kingdom (if realised) comes at an incredible cost, for the real child is required to vacate the imaginative space of its own dreaming, for the adult who claims this territory as its own.

\section{The narrative voice and displacement}

In the conclusion of this narrative, the narrating voice is displaced, through a metonymic 'tagging', onto an aiminhibited and asexual relationship between sisters. By projecting Alice's continued entrapment into the future, it is anticipated that she will repeat this cycle of her subordination by repeating 'many a strange tale, perhaps even with the dream of Wonderland of long ago' (p.164) to her own and other children. This impossible plea, a fantasy for immortal love from the narrating consciousness, reveals the desire of the writing subject. The author-function that appeals for eternal love is however, not predicated on a model of productivity (a communion or poiesis) but is instead based on a deconstructive ideology whose function is to contain and assimilate such objects. Furthermore, it is impossible that the other can meet this demand, as desire is, in this instance, founded on an imaginary identification, which is the supplementation of the lacking self through the other.

In summary, to reconfigure Alice's role in this text, problematic elements, such as the narrative's coercive textual strategies, and themes (in particular, its counter narratives of desire) must be analysed and positioned within broader cultural debates. For Carroll uses particular textual strategies, including the gaze, which associates seeing 'as textual/sexual and reading as seeing' (Kincaid 1992, p.303), to construct and potentially entrap children per se within, and by, certain discourses. In Alice's Adventures in Wonderland this occurs through an alignment of childhood and the gaze as sites of knowledge, or as repositories of 'absolute' trith, innocence or value.

Further, while the specular, textual and imaginative appropriation and maintenance of an object or visual image is, for some perceiving subjects, a matter of ontological life or death (the loss of the image equates to the loss of self or object) this, nonetheless, is a colonising act. This colonising impuise is also revealed in Carroll's privileging of a developmentally 'arrested' relationship between the child and time. Recognition of the 
unconscious structure and colonising impuise embedded in this narrative thus enables it to read as a narrative of desire, like other discourses that inform images of the child, and the field of representation of children in general.

\section{NOTES}

1. I draw here on James Kincaid's formulation, that the 'division between adult and child ... [is] ... a dissociation which ... has been at least for the past two hundred years heavily eroticized: the child is that species which is free of sexual feeling or response; the adult is that species which has crossed over into sexuality' (1992, pp.6-7).

2. See Kincaid: 'The other is that which we place outside our perceptual field, which we will not allow our metaphorical lens to cover. On the other hand, this impossibility, this that which is not, becomes the core of erotic energy. We need very badly this otherness, this elusive image that evades our mechanisms of explanation, this lack that will fuel desire. So we stage the gaps and eroticize them' (p. 32).

\section{REFERENCES}

Barthes, Roland (1994) The Pleasures of the Text. New York, Hill and Wang.

Carroll, Lewis (1970) The Annotated Alice. London, Penguin.

Foucault, Michel (1977) Language, Counter-Memory, Practice. London, Basil Blackwell.

Freud, Sigmund (1982) Introductory Lectures on Psychoanalysis. London, Penguin.

Irigaray, L. (1983) 'Veiled Lips', Mississippi Review, 11, 3: 99.

Kincaid, James (1992) Child-Loving: The Erotic Child and Victorian Culture. London, Routledge.

Lacan, Jacques (1994) Four Fundamental Concepts of Psychoanalysis. London, Penguin.

McGillis, Roderick (1986) “"What is the fun?" said Alice', Children's Literature in Education 17, 1: 25-36.
Perrot, Michelle (ed) (1990) A History of Private Life: From the Fires of Revolution to the Great War. London, Belknap Press of Harvard University Press.

Tatar, Maria (1992) Off With Their Heads! Fairy Tales and the Culture of Childhood. Princeton, Princeton University Press.

Vink, E. (Producer) (1998) Alice's Adventures in Wonderland. Television/Documentary Series. A Discovery Production.

Wynne-Davies, Marion (ed) (1989) Bloomsbury Guide to English Literature. London, Bloomsbury.

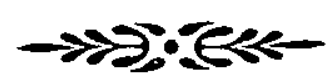

\section{BIOGRAPHICAL NOTE}

Rachael Cameron is a literary critic, poet and fiction writer. She completed her Bachelor of Arts (Honours) at Monash University in 1997, and is currently completing her $\mathrm{PhD}$ in literary and cultural studies at the University of Melbourne. Rachael's writing credits include a short play (MUDfest5), essays in children's literature and performance poetry at Queensland and Victorian venues as well as community radio, and she has had poetry published in Australian Multicultural Book Review.

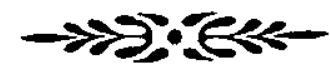

